\title{
Incidência de Colletotrichum graminicola em colmos de genótipos de milho
}

\author{
Rodrigo Véras da Costa ${ }^{1}$, Dagma Dionísia da Silva², Luciano Viana Cota ${ }^{3}$, Douglas Ferreira Parreira ${ }^{4}$, Alexandre da \\ Silva Ferreira ${ }^{5}$, Carlos Roberto Casela ${ }^{6}$
}

1,3,5, ${ }^{6}$ Pesquisador Centro Nacional de Pesquisa de Milho e Sorgo, EMBRAPA, CEP 35701-970, C.P. 285, Sete Lagoas, MG, ferreira@ cnpms.embrapa.br; ${ }^{2}$ Doutoranda Departamento de Fitopatologia da Universidade Federal de Lavras, 37200-000, Lavras, MG. bolsista do CNPq, ddionisia@ yahoo.com.br; ${ }^{4}$ Doutorando Departamento de Fitopatologia da Universidade Federal de Viçosa, 36570-000, Viçosa, MG, bolsista da CAPES, douglas2002ufv@yahoo.com.br

Autora para correspondência: Rodrigo Véras da Costa (veras@cnpms.embrapa.br)

Data de chegada: 12/08/2008. Aceito para publicação em: 11/03/2010.

\section{RESUMO}

Costa, R.V.; Silva, D.D; Cota, L.V.; Parreira, D.F.; Ferreira, A. S.; Casela, C.R.. Incidência de Colletotrichum graminicola em colmos de genótipos de milho. Summa Phytopathologica, v.36, n.2, p.122-128, 2010.

A podridão do colmo, causada por Colletotrichum graminicola, é uma das mais severas doenças da cultura do milho no Brasil, principalmente se ocorrer após a fase de florescimento, por causar perdas significativas na produtividade. A melhor alternativa para o controle da doença é a utilização de cultivares geneticamente resistentes. O objetivo deste trabalho foi avaliar a incidência da podridão de colmo em híbridos comerciais de milho, tendo em vista a pouca disponibilidade de informações que permitam a utilização da resistência genética como estratégia para o controle desta doença. Foram avaliados 18 híbridos comerciais de milho, em três ensaios conduzidos nos anos de 2005, 2006 e 2007 na área experimental da Embrapa Milho e Sorgo, sob condições de inóculo natural. Em cada parcela foram coletados fragmentos do colmo de três plantas, sendo: o segundo entrenó acima do solo, o entrenó de inserção da espiga e o entrenó localizado abaixo do pendão. Quatro fragmentos de cada parte foram desinfestados e transferidos para placas de Petri contendo meio de farinha de aveia - ágar (FAA). As placas foram mantidas em câmara de incubação sob luz fluorescente contínua à temperatura de $25^{\circ} \mathrm{C}$, seguindo-se a identificação e quantificação do patógeno após três a quatro dias de incubação. As menores incidências (abaixo de 30\%) foram observadas nos híbridos BR201 e BR206 e a maior incidência (acima de 60\%) detectada no híbrido BRS1010. O patógeno foi detectado em todos os segmentos do colmo analisados, predominando, entretanto, no terço médio superior para a maioria dos híbridos avaliados. Apesar da variação observada entre os genótipos quanto à incidência da antracnose no colmo, nenhum híbrido pôde ser considerado como de altamente resistente ao patógeno.

Palavras-chave adicionais: Colletotrichum graminicola, Zea mays, podridão do colmo.

\begin{abstract}
Costa, R.V.; Silva, D.D; Cota, L.V.; Parreira, D.F.; Ferreira, A. S.; Casela, C.R.. Incidence of Colletotrichum graminicola in stalk from maize genotypes. Summa Phytopathologica, v.36, n.2, p.122-128, 2010.

Stalk rot (Colletotrichum graminicola) is one of the most serious disease affecting maize crop in Brazil, especially after the flowering phase, when yield losses can reach significant levels. The use of genetically resistant cultivars is the most efficient strategy to control the disease. The aim of this work was to evaluate the incidence of stalk rot in maize commercial hybrids sinde there is scarce information to allow the use of genetic resistance as a strategy to control this disease. Eighteen maize commercial hybrids were evaluated in 2005, 2006, and 2007 in the experimental area of EMBRAPA Maize and Sorghum Research Center Sete Lagoas, Minas Gerais State, Brazil, under conditions of natural infection. From each plot, three stalk segments of three plants were sampled:

the second internode above the soil line, the internode of ear insertion, and the internode right bellow the tassel. Four tissue fragments of each stalk segment were surface sterilized and transferred to oatmeal agar plates, which were incubated under continuous fluorescent light at $25^{\circ} \mathrm{C}$. Pathogen identification and quantification were performed after three to four days of incubation. The hybrids BR201 and BR206 showed the lowest infection level (below 30\%) whereas the highest incidence (above $60 \%$ ) was observed for the hybrid BRS1010. The pathogen was observed in all analyzed stalk segments, but was most frequently isolated from the internode right below the tassel. No evaluated hybrid could be considered to have high resistance to the pathogen.
\end{abstract}

Keywords: Colletotrichum graminicola, Zea mays, stalk rot

Dentre as atividades agrícolas no Brasil, a produção de grãos é uma das mais importantes, na qual a cultura do milho tem papel de destaque. O Brasil é o terceiro maior produtor de milho do mundo, depois dos Estados Unidos e China. Também destaca-se como um dos principais fornecedores de carne para o mundo, fator que mantém elevado o consumo interno desse grão (11) pelo uso na alimentação animal.

Nos últimos anos, a produção de milho no Brasil vem experimentando aumentos expressivos, decorrentes da evolução do 
sistema de cultivo, da disponibilidade de genótipos mais produtivos e melhor adaptados às diferentes regiões, da mecanização, do aumento da área de plantio, do cultivo na safrinha e do avanço da cultura para novas regiões do Centro Oeste e Nordeste. Nos últimos 15 anos a produção desse grão praticamente dobrou, passando de 24 para 42 milhões de toneladas, com aumento de produtividade de $1800 \mathrm{Kg} / \mathrm{ha}$ para mais de $3.000 \mathrm{Kg} / \mathrm{ha}(7)$.

A produtividade média brasileira, de $3500 \mathrm{~kg} / \mathrm{ha}$, ainda é considerada baixa quando comparada a outros países produtores, como China, (5.000 kg/ha), Argentina (7.000 kg/ha) e Estados Unidos $(9.000$ $\mathrm{kg} / \mathrm{ha}$ ). Dentre os fatores que, atualmente, contribuem para a baixa produtividade do milho no Brasil as doenças são consideradas como um dos mais importantes (18). Dentre elas, as podridões de colmo destacam-se entre as mais severas doenças e vem causando grande preocupação devido aos danos causados à cultura (4). As podridões promovem danos diretos pela colonização dos tecidos vasculares do colmo pelos patógenos, reduzindo o enchimento dos grãos e causando a morte prematura das plantas. Também podem promover o tombamento das plantas, dificultando a colheita mecânica e expondo as espigas à ação de roedores e podridões devido o contato com o solo $(6,20)$. Como os patógenos causadores de podridões sobrevivem no solo e em restos culturais, plantios sucessivos, com ampla adoção do sistema plantio direto, sem rotação de culturas, favorecem a ocorrência das doenças pelo rápido acúmulo de inóculo na área de cultivo.

As podridões de colmo têm como agentes diferentes patógenos, como fungos e bactérias (1). No Brasil os principais fungos são: Colletotrichum graminicola (Ces.) G.W. Wils., Stenocarpella maydis (Berk) Sacc, Stenocarpella macrospora Earle, Fusarium graminearum Schwabe, F. moniliforme Sheld e F. moniliforme var. subglutinans Wr. $\&$ Reink (2,8). Apesar de muitos desses patógenos incidirem simultaneamente no milho, um grupo está mais freqüentemente associado à podridão do colmo em determinada região. Também a dominância das espécies, e a sua diversidade, podem ser alteradas tanto dentro da época de crescimento como gradualmente através do tempo com mudanças de práticas culturais e introdução de híbridos (13).

Dentre os principais patógenos causadores de podridões de colmo no milho, destaca-se o fungo Colletotrichum graminicola, causador da antracnose, o qual pode atacar qualquer parte da planta e em todos os estádios de crescimento da cultura (3) e causar perdas significativas, situando-se dentre as mais importantes e que desafiam o melhoramento genético (24). A fase foliar da doença causa maiores danos e ocorre nos estádios de plântulas e em plantas velhas, enquanto a antracnose do colmo é mais severa em plantas maduras ou próximo à antese.

Como sintomas externos da antracnose do colmo, tem-se uma descoloração escura brilhante dos tecidos da casca. Num corte longitudinal do colmo pode ser observado o escurecimento e apodrecimento dos tecidos internos (3). Os entrenós podres levam a planta ao enfraquecimento, acamamento e, também, a degeneração dos tecidos do colmo causando a morte prematura das partes superiores da planta, sintoma conhecido como "dieback" (24). Uma relação sinergística tem sido estabelecida entre ferimentos causados por insetos e a incidência da antracnose no colmo $(13,23)$. Entretanto, a podridão do colmo pode ocorrer com frequência na ausência de ferimentos, como tem sido obsevado em plantas de milho Bt $(13,23)$. Gatch et al. (2002a) observaram que híbridos Bt foram mais suscetíveis que os híbridos não $\mathrm{Bt}$, indicando que novas estratégias para o controle da podridão do colmo devem ser buscadas. Assim, o conhecimento a respeito de como o patógeno se distribui na planta, seu comportamento em relação a híbridos resistentes e suscetíveis e a influência do ambiente na manifestação da doença são importantes.

Dessa forma, este trabalho teve como objetivo avaliar a incidência de C. graminicola em diferentes partes de colmos de genótipos de milho, em diferentes safras.

\section{MATERIAL E MÉTODOS}

Os ensaios foram conduzidos na área experimental do Centro Nacional de Pesquisa de Milho e Sorgo - CNPMS - Embrapa, em Sete Lagoas - MG, nas safras: verão 2005/2006, safrinha de 2006 e, verão 2006/2007. Foi avaliado um conjunto de 18 genótipos de milho, constituído por híbridos da EMBRAPA e de outras empresas (Tabela 1). A fonte de inóculo foi constituída por inóculo sobrevivente em palhada de milho de plantios anteriores. As semeaduras foram realizadas em 01/12/2005, 15/02/2006 e 11/12/2006, respectivamente, para as três safras.

Tabela 1. Relação e descrição dos genótipos de milho utilizados para a condução dos experimentos.

\begin{tabular}{lccc}
\hline Genótipos & Empresa & Tipo híbrido & Ciclo \\
\hline BR 201 & Embrapa & HD & $\mathrm{P}$ \\
BR 205 & Embrapa & HD & $\mathrm{P}$ \\
BR 206 & Embrapa & HD & $\mathrm{P}$ \\
BRS 3123 & Embrapa & H T & SP \\
BRS 2110 & Embrapa & HD & P \\
BRS 3150 & Embrapa & H T & P \\
BRS 2114 & Embrapa & HD & SP \\
BR 106 & Embrapa & V & SMP \\
BRS 1010 & Embrapa & HS & P \\
BRS 2020 & Embrapa & HD & P \\
BRS 1001 & Embrapa & HS & P \\
BRS 3003 & Embrapa & HT & P \\
BRS 2223 & Embrapa & HD & SP \\
BRS 1030 & Embrapa & HS & P \\
BRS 1031 & Embrapa & HS & P \\
BRS 1035 & Embrapa & HS & P \\
P30F80 & Pioneer & HS & SMP \\
AG 1051 & Monsanto & HD & SMP \\
\hline
\end{tabular}

HS: Híbrido simples; HD: Híbrido duplo; HT: Híbrido Triplo; V: variedade; P: Precoce; SP: Superprecoce; SMP: semiprecoce

A semeadura foi realizada de forma direta sobre a palhada de milho, em espaçamento de $0,8 \mathrm{~m}$ entre fileiras e, aproximadamente, cinco plantas por metro após o desbaste. A adubação de base, para os três experimentos, foi de $300 \mathrm{Kg} / \mathrm{ha}$ da fórmula 4-30-16 (N-P-K) + $\mathrm{Zn}$. As adubações de cobertura com nitrogênio foram realizadas aos 20 e 30 DAE, através da aplicação de $40 \mathrm{~kg} / \mathrm{ha}$ de uréia.

O delineamento experimental foi o de blocos ao acaso com 18 tratamentos e três repetições, sendo cada parcela constituída de três fileiras de plantas e cinco metros de comprimento. Durante o ciclo da cultura foram realizados todos os tratos culturais necessários e coleta de dados climáticos das três safras.

Fragmentos de colmos foram coletados e encaminhados para avaliações em laboratório. De cada planta foram coletados três entrenós 


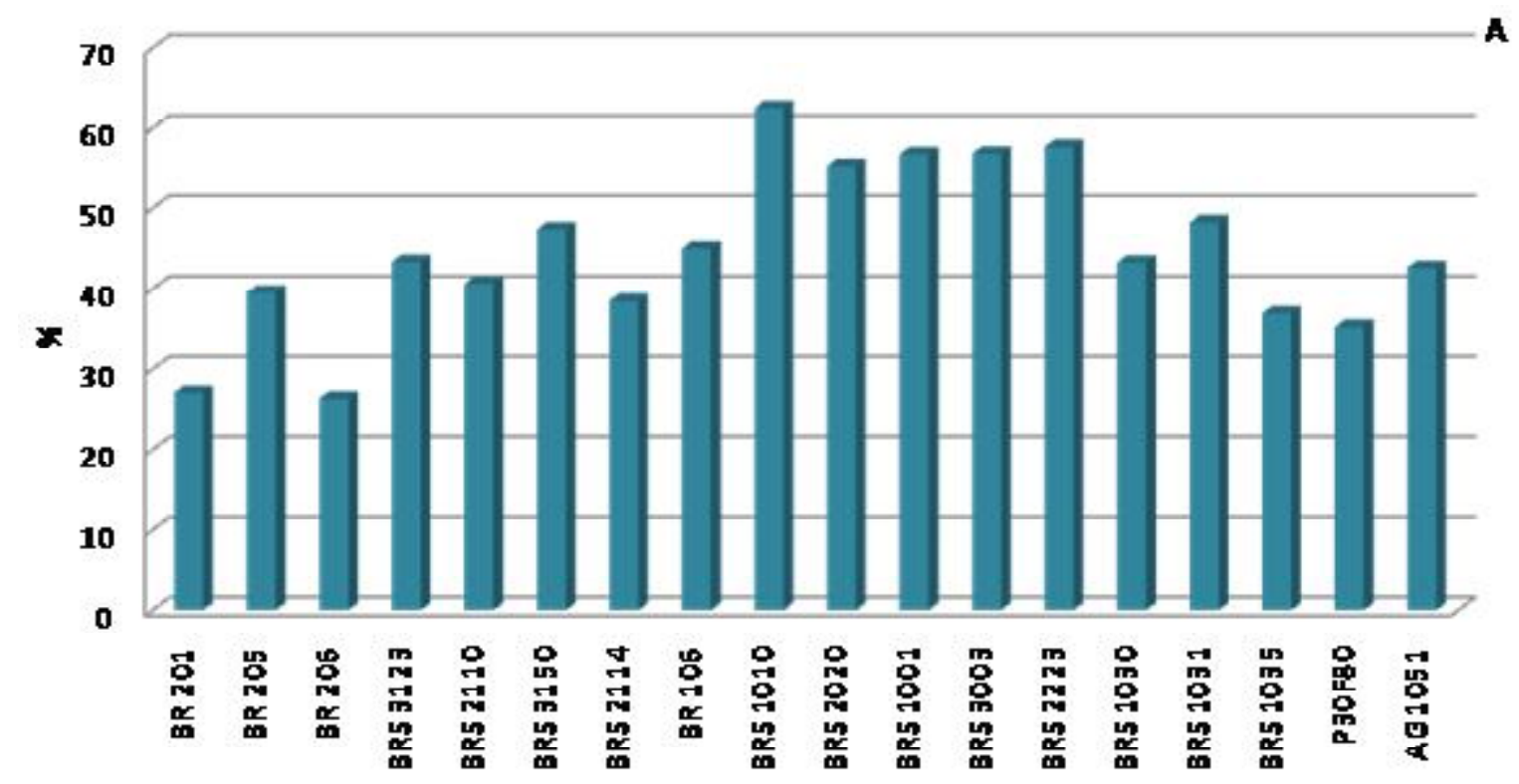

Figura 1. Incidencia media (satra $\angle U U J / \angle U U D$, satrınna $\angle U U D$ e satra $\angle U U D / \angle U U$ /) de colletotrıchum gramınıcola, causando podridão de colmo em diferentes genótipos de milho. Resultados obtidos através do isolamento de fragmentos de colmo.

do colmo: do segundo entrenó acima do solo, do entrenó da inserção da espiga e do entrenó localizado abaixo do pendão. Após a coleta, os entrenós do colmo foram raspados, principalmente na junção da bainha, lavados com detergente e água corrente, para evitar contaminação por saprófitos e, posteriormente, mantidos em condição ambiente para secagem. Para os isolamentos, os entrenós foram pulverizados com álcool $70 \%$ e flambados. Posteriormente, procedeu-se a retirada de parte da casca e quatro fragmentos da parte interna dos entrenós foram transferidos para placas de Petri contendo meio de farinha de aveia. As placas foram incubadas sob luz fluorescente contínua, na temperatura de $25{ }^{\circ} \mathrm{C}$, sendo a identificação e a quantificação do patógeno realizadas após três a quatro dias de incubação. Foram considerados resistentes os genótipos para os quais não foram detectados patógenos nos fragmentos coletados.

\section{RESULTADOS E DISCUSSÃO}

Houve diferença na incidência de $C$. graminicola entre híbridos e entre as safras. De acordo com os dados médios das três safras, a incidência de C. graminicola variou de 26,3 a $62,5 \%$. Quanto ao desempenho individual, os menores níveis médios de incidência nas três safras, foram verificados para os híbridos BR201 e BR206, com valores abaixo de 30\%. Os híbridos BR205, BRS2110, BRS2114, BRS1035 e P30F80, mantiveram níveis entre 30 e 40\%, e a maior incidência foi observada para o híbrido BRS1010, com valor acima de $60 \%$ (Figura 1). Na safra de verão 2006/2007, a incidência de $C$. graminicola apresentou um padrão semelhante ao observado na safra de verão 2005/2006, embora com valores mais elevados. Na safrinha, os valores de incidência foram menores em relação às safras de verão, exceto para os híbridos BRS1010 (74,76\%) e BRS2223 (63,87\%) em relação à safra 2005/2006 (Figura 2).

Considerando a média das safras e dos híbridos, a incidência de $C$. graminicola na base do pendão, no entrenó da espiga e na base do colmo foi de 51,6, 45,8 e 35,2 \%, respectivamente (Figura 3). A maior incidência do patógeno, em relação à posição no colmo, ocorreu no terço médio superior, exceto para os híbridos BR205, BR106, BRS1001 e AG1051, os quais apresentaram uma maior incidência na base do colmo (Figura 3). Nos híbridos BR206, BRS1010, BRS1001 e AG1051, a incidência do patógeno na parte mediana foi maior que a observada nas partes superior e basal do colmo. De modo geral, observou-se que o patógeno se distribuiu amplamente por toda a extensão do colmo.

Os dados obtidos no presente trabalho evidenciam a predominância de C. graminicola como agente causal da podridão de colmo do milho na área experimental do CNPMS - Embrapa. Considerando a ausência de diferenças significativas nas condições climáticas (temperatura, umidade relativa e precipitação) prevalecentes durante as safras de verão, a predominância de C. graminicola na safra 2006/2007 ocorreu, provavelmente, devido ao maior potencial de inóculo na área de plantio. Segundo Gilbertson et al. (14), C. graminicola e G. zeae são os patógenos mais agressivos dentre as espécies causadoras de podridão de colmo em milho. Os resultados aqui obtidos corroboram com a observação dos referidos autores. Além disso, as condições de clima no decorrer das duas safras de verão mencionadas acima, principalmente com relação à temperatura e precipitação (Figuras 4 e 5), foram favoráveis ao desenvolvimento da antracnose. Denti \& Reis (8), em levantamento e quantificação de fungos associados à podridão do colmo na região do Planalto Gaúcho, verificaram, na safra 1997/1998, predominância de $C$. graminicola em relação a outros patógenos como F. moniliforme, D. macrospora e D. maydis. Segundo os autores, a maior quantidade de chuva ocorrida durante o período de crescimento e desenvolvimento da cultura, em relação à média de anos anteriores, foi o fator determinante para a elevada incidência de $C$. graminicola. Casa et al. (5), detectaram C. graminicola, além de Fusarium graminearum, em maior incidência em colmos sintomáticos de dois híbridos em duas safras. Os autores justificaram a maior incidência de C. graminicola devido à existência de hospedeiros secundários do patógeno, tais como Brachiaria plantaginea L. e Digitaria sanguinalis $\mathrm{L}$.

A precipitação total acumulada no período de fevereiro a maio de 2006 (Safrinha) foi, aproximadamente, 57 e 85 \% inferior à registrada 

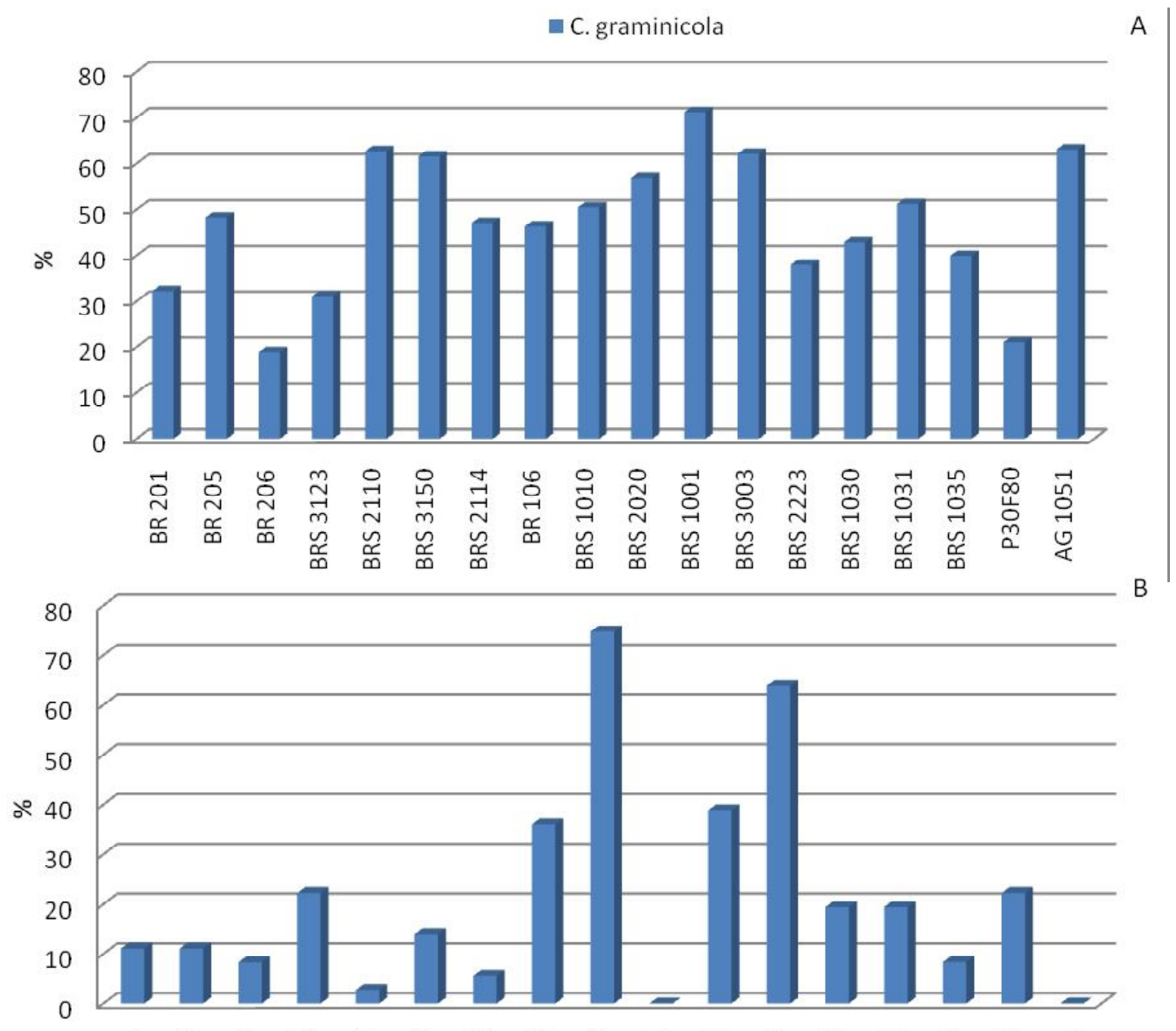

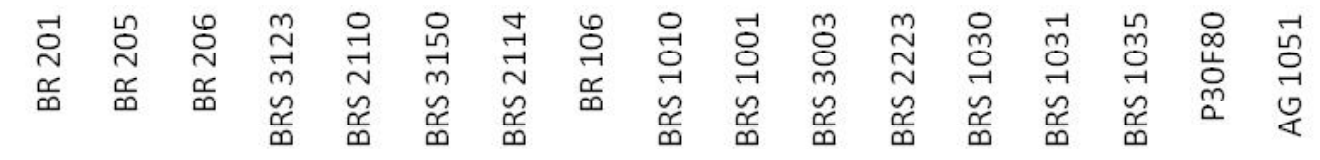

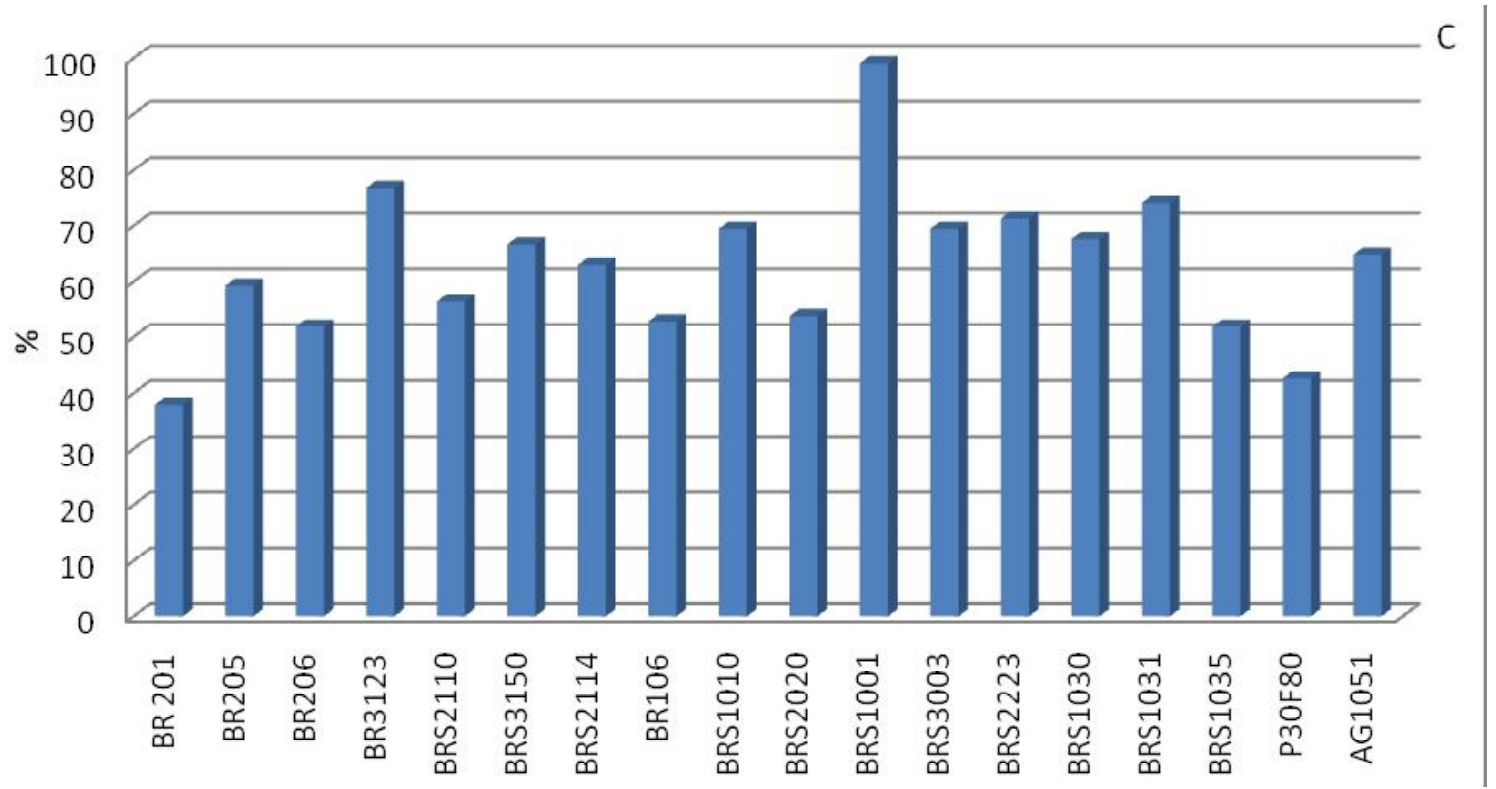

Figura 2. Incidência de C. graminicola em diferentes genótipos de milho nas safras: verão 2005/2006 (A), Safrinha 2006 (B) e verão $2006 / 2007$ (C). 

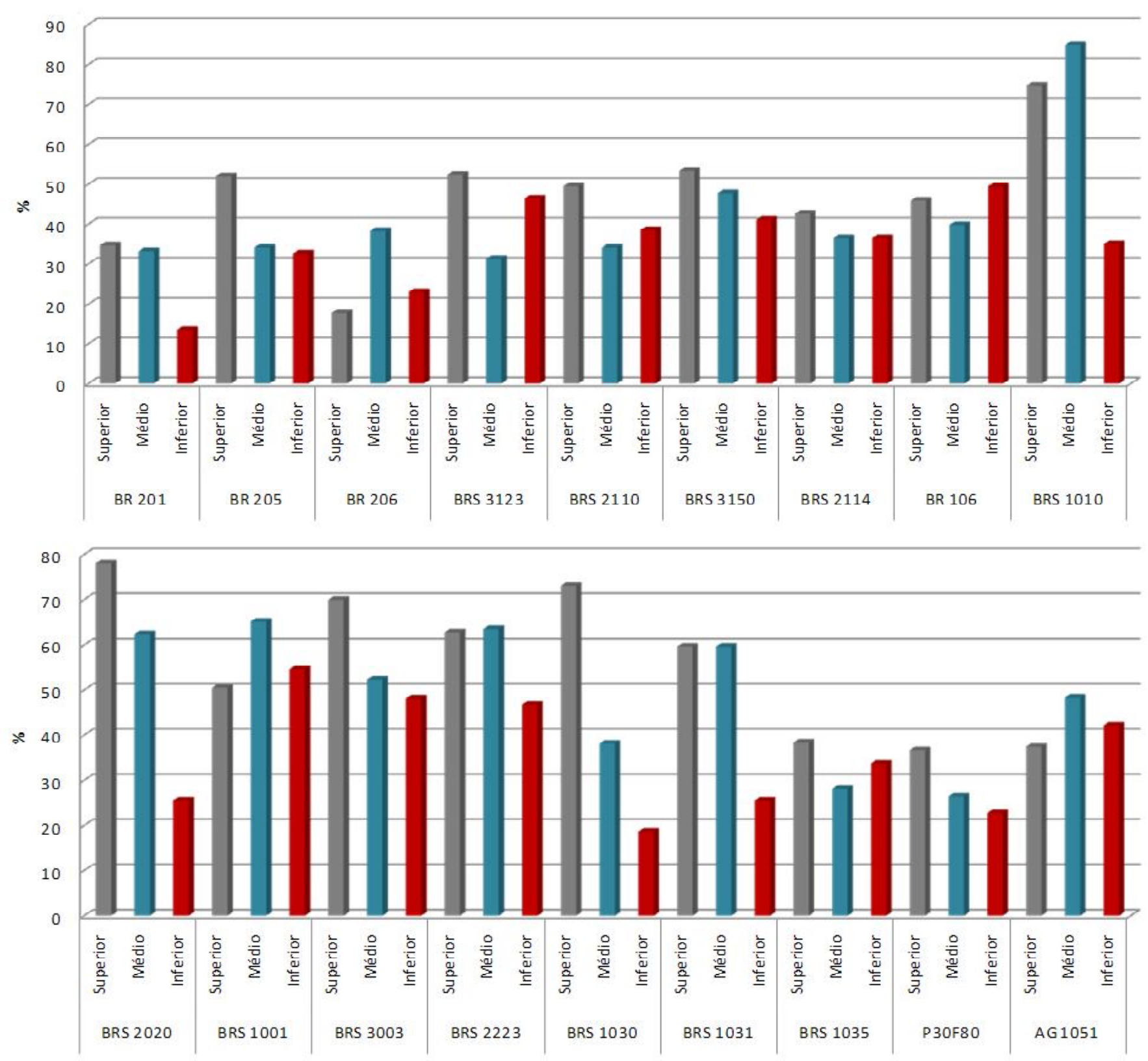

Figura 3. Incidência média de C. graminicola em híbridos de milho considerando diferentes posições no colmo das plantas: 1) Superior: Isolamento realizado no entrenó da base do pendão; 2) Médio: isolamento realizado no entrenó de inserção da espiga no colmo; e 3) Inferior: isolamento realizado no segundo entrenó acima do solo. Os valores são correspondentes às médias das três safras.

nas safras de verão 2005/2006 e 2006/2007, respectivamente (Figura 4). A temperatura média do mesmo período foi $1,3^{\circ} \mathrm{C}$ menor na safrinha quando comparada às duas safras de verão (Figura 4). Nas safras de verão não foram registradas temperaturas mínimas inferiores a $15^{\circ} \mathrm{C}$, enquanto, na safrinha, foram registradas temperaturas em torno de 7 a $8{ }^{\circ} \mathrm{C}$. Considerando que as condições de ambiente favoráveis ao patógeno, são caracterizadas por elevadas temperaturas, umidade relativa do ar e precipitação $(6,16)$, é provável que a menor incidência média de $C$. graminicola, verificada para o ensaio conduzido na safrinha de 2006, tenha sido determinada pelas condições climáticas prevalecentes.

Segundo Denti et al. (9) e Latterell e Rossi (15), apesar dos sintomas de podridão serem observados em todo o colmo, estes ocorrem com maior frequiência e intensidade na base da planta. Os resultados obtidos no presente trabalho demonstraram que $C$. graminicola ocorreu em toda a extensão do colmo, com predominância no terço médio superior. A ocorrência de podridão de colmo é resultante de infecções primárias nas raízes (22) e folhas (23). Portanto, é provável que a posição em que o fungo ocorre com maior frequência no colmo esteja relacionada à origem do inóculo. Entretanto, permanecem dúvidas sobre os fatores que controlam a ocorrência dos sintomas de "dieback" e a relação deste com a resistência em genótipos de milho.

De fato, uma rápida dispersão longitudinal do patógeno foi observada por Venard \& Vaillancourt (24), porém não ocorrendo via xylema ou floema. Segundo estes autores, a dispersão primária foi devido à produção e elongação de hifas dentro das fibras celulares, as quais se encontram associadas aos feixes vasculares e à casca. Duas fases foram observadas durante a infecção e colonização dos colmos, 


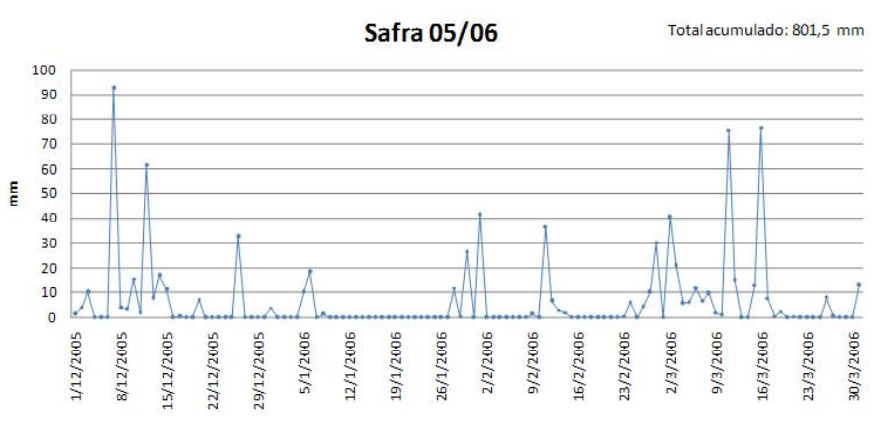

Safrinha 2006

Totalacumulado: $510,1 \mathrm{~mm}$

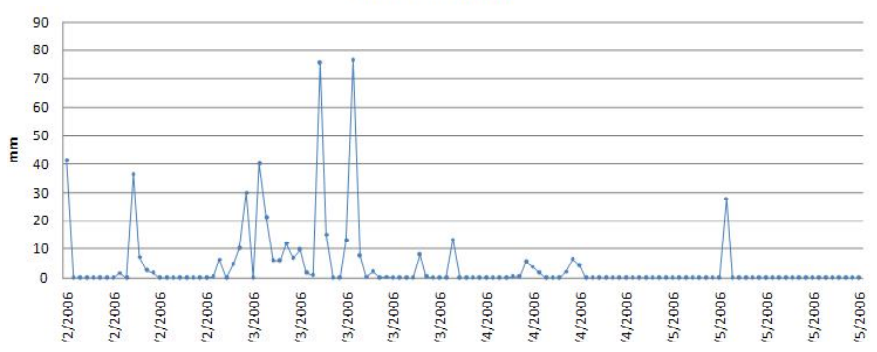

Satra 06/07

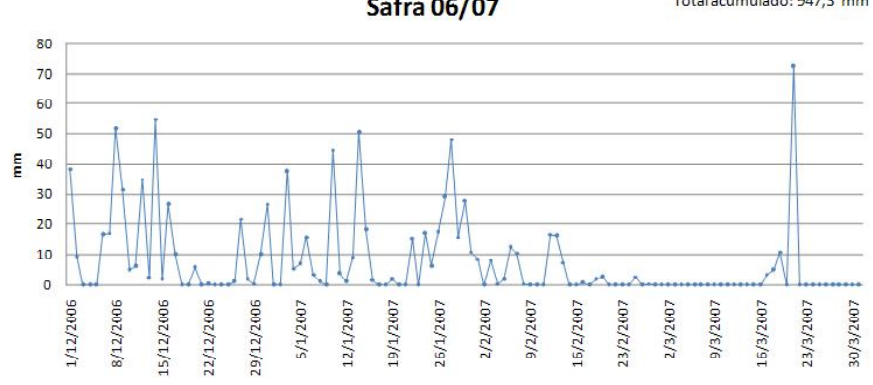

Figura 4. Precipitação diária $(\mathrm{mm})$ durante o período de condução dos ensaios nas três safras.

uma em que a lesão primária se elongou por colonização e expansão por meio das fibras associadas aos feixes vasculares e casca, e outra, em que ocorre a produção de lesões secundárias descontínuas distantes do sítio ferido. Observou-se que $C$. graminicola é um colonizador eficiente de fibras celulares localizadas abaixo da casca do colmo. Usando estas células, o fungo se move rapidamente por meio dos entrenós a partir de um ponto inicial de inoculação, o que pode explicar sua ocorrência em toda a extensão do colmo. Nos casos em que houve predominância no terço superior, uma provável explicação é o fato dos feixes das folhas estarem em conexão direta com a bainha $(23,24)$. Neste último caso, a doença ocorreria se o isolado fosse virulento à folha e ao colmo, considerando a hipótese da existência de controle genético da resistencia à antracnose distinto nas folhas e colmo, resistência essa denominada de "resistência de órgão específico" $(22,23,24)$.

Aparentemente, não há uma relação entre a posição do patógeno no colmo e a resistência genética, visto que tanto híbridos com menores valores de incidência (BR201 e BR206), quanto outros com niveis de incidência mais elevados (BRS2020 e BRS3003) apresentaram maior ocorrência de $C$. graminicola no terço médio superior. Coincidentemente, todos os híbridos que tiveram maior incidência do patógeno na base do colmo, tiveram incidência média da doença acima de $35 \%$. Venard \& Vaillancourt (23) não verificaram efeito significativo entre a posição ou o número de entrenós inoculados por planta e o tamanho de lesão, o que reforça a idéia de que não há relação entre a
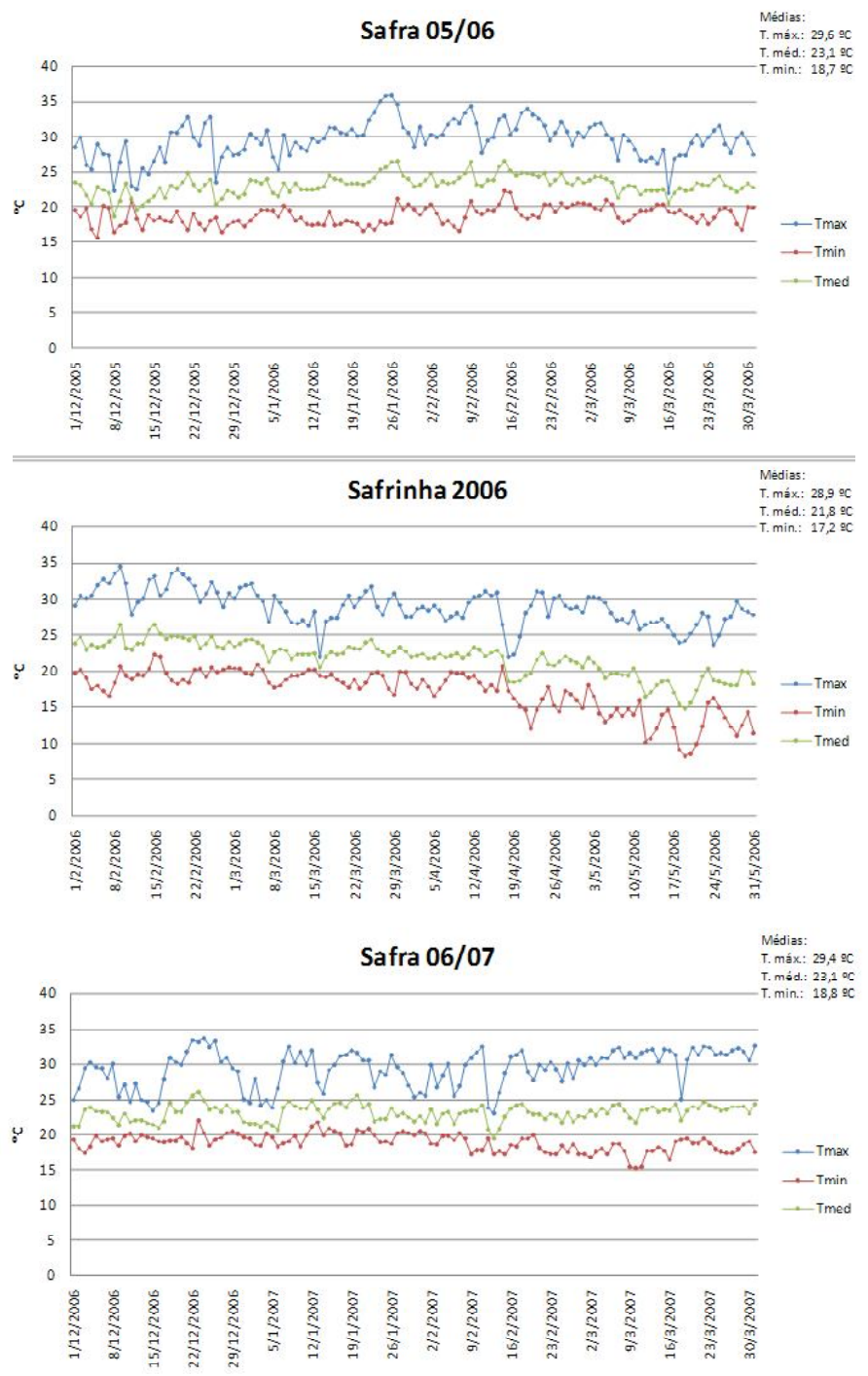

Figura 5. Temperaturas máximas, médias e mínimas diárias $\left({ }^{\circ} \mathrm{C}\right)$ durante o período de condução dos ensaios nas três safras.16/2/2006

posição de $C$. graminicola no colmo e a resitência genética.

A variação no nível de resistência ou suscetibilidade, verificada entre os híbridos avaliados no presente trabalho, confirma a existência de variabilidade no germoplasma de milho ao referido patógeno, relatada em estudos anteriores $(8,16,17,19,21)$. Segundo Denti et al., (9) e Fosket (10), genótipos que apresentam colmo com coloração púrpura a roxo intensa apresentam menor incidência de podridão na base do colmo, indicando o possível envolvimento da pigmentação com a resistência a doença. Ainda, em genótipos resistentes à podridão do colmo, os danos são usualmente limitados a poucos entrenós adjacentes, que podem não tornar-se apodrecidos, principalmente após a antese $(1,24)$.

De acordo com os resultados deste trabalho, conclui-se que a incidência de podridão do colmo está relacionada com o genótipo e as condições ambientais em cada safra. Em genótipos suscetíveis, $C$. graminicola ocorreu amplamente por toda extensão do colmo causando seca precoce da planta. Apesar da variação observada entre os genótipos avaliados nas diferentes épocas de plantio quanto à incidência da antracnose no colmo, nenhum híbrido pôde ser considerado como resistente ao patógeno. 


\section{REFERÊNCIAS BIBLIOGRÁFICAS}

1. Anderson, B.; White, D.G. Evaluation of methods for identification of corn genotypes with stalk rot and lodging resistance. Plant Disease, Quebec, v. 78, p. 590-593, 1994.

2. Balmer, E.; Pereira, O.A.P. Doenças do milho. In: Paterniani, E.; Viégas, G.P. (Eds.) Melhoramento e produção de milho. 2. ed. Campinas: Fundação Cargill, 1987, p. 595 - 634.

3. Bergstrom, G.C., Nicholson, R.L. The biology of corn anthracnose knowledge to exploit for improved management. Plant Disease, Quebec, v. 83, n. 7, p. 596-608, 1999.

4. Blum, L.E.B.; Sangoi, L.; Amarante, C.V.T. do; Arioli, C.J.; Guimarães, L.S. Desfolha, população de plantas e precocidade do milho afetam a incidência e a severidade de podridões do colmo. Ciência Rural, Santa Maria, RS, v. 33, n. 5, p. 805 - 811. 2003.

5. Casa, R.T.; Moreira, E.N.; Bogo, A.; Sangoi, L. Incidência de podridões do colmo, grãos ardidos e rendimento de grãos em híbridos de milho submetidos ao aumento na densidade de plantas. Summa Phytopathologica, Botucatu, SP, v.33, n.4, p.353-357, 2007.

6. Casela, C.R.; Ferreira, A.F.; Pinto, N.F.J.A. Doenças na cultura do milho. Circular Técnica, EMBRAPA/CNPMS, Sete Lagoas, MG, n. 83, 2006. 14p

www.conab.gov.br/conabweb/. Acesso em 14 de abril de 2007.

8. Denti, E.A.; Reis, E.M. Levantamento de fungos associados às podridões de colmo e quantificação de danos em lavouras de milho do Planalto Médio Gaúcho (RS) e dos campos gerais do Paraná. Fitopatologia Brasileira, Brasília, v. 28, n. 6, p. 585 - 590 . 2003.

9. Denti, E.A.; Reis, E.M.; Forcelini, C.A. Reação de genótipos de milho às podridões da base do colmo (PCB). Summa Phytopathologica, Botucatu, SP, v. 28, n. 3, p. 286 - 288, 2002.

10. Fosket, D.E. Plant growth and development: A molecular approach. San Diego: Academic Press, 1994. 580p.

11. Garcia, J.C.; Mattoso, J.M.; Duarte, J.O.; Cruz, J.C. Aspectos econômicos da produção e utilização do milho. Circular Técnica, EMBRAPA/CNPMS, Sete Lagoas, MG, n. 74, 2006. 12p.

12. Gatch, E. W., Hellmich, R. L., Munkvold, G. P. A comparison of maize stalk rot occurrence in Bt and non-Bt hybrids. Plant Disease, Quebec, v.86, p.1149-1155, 2002a.

13. Gatch, E. W., Munkvold, G. P. Fungal species composition in maize stalks in relation to European corn borer injury and trans- genic insect protection. Plant Disease, Quebec, v.86, p.1156$1162,2002 b$

14. Gilbertson, R.L., Brown, W.M.Jr.; Ruppel, E.G. Prevalence and virulence of $F$. moniliforme. associated with stalk rot of corn in Colorado. Plant Disease, St. Paul, v. 69, p. 1065 - 1068, 1985.

15. Latterell, F.M.; Rossi, A.E. Stenocarpella macrospora (=Diplodia macrospora) and $S$. maydis (=D. maydis) compared as pathogens of corn. Plant Disease, St. Paul, v. 67, n. 7, p. $725-$ $729,1983$.

16. Matiello, R.R. Patossistema Milho x Colletotrichum graminicola: Estudo da herança, mapeamento de genes de resistência e estimativas de danos na produção. 2004. 115P. Tese (Doutorado em Genética e Melhoramento de Plantas). Escola superior de Agricultura "Luiz de Queiroz”, Universidade de São Paulo, Piracicaba.

17. Nazareno, N.X.R. Avaliação de perdas por podridão de colmo em milho (Zea mays L.) no estado do Paraná. Fitopatologia Brasileira, Brasília, v. 14, p. 82 - 84. 1989.

18. Pereira, O.A.P.; Carvalho, R.V.; Camargo, L.E.A. Doenças do milho. In: H. Kimati, L. Amorim, J.A.M. Rezende, A. Bergamin Filho, L.E.A. Camargo. Manual de Fitopatologia, Editora Ceres, p. 477 - 488. 2005.

Lev. e rusarlum monilforme sneid. em colmo ae minno. summa Phytopathologica, Botucatu, SP, v. 2, p. 165 - 171. 1976.

20. Reis, E.M.; Casa, R.T. Manual de identificação e controle de doenças do milho. Passo Fundo: Aldeia Norte, 1996. 78p.

21. Silva, H.P.; Pereira, O.A.P.; Miranda Filho, J.B.; Balmer, E. Herança da resistência a antracnose foliar (Colletotrichum graminicola) em milho. Fitopatologia Brasileira, Brasília, v. 11, n. 3, p.617 - 6231986

22. Sukno, S.A.; García, V.M.; Shaw, B.D.; Thon, R.M. Root infection and systemic colonization of maize by Colletotrichum graminicola. Applied and Enviromental Microbiology, Washington, DC, v. 74, n.3, p. 823-832, 2008.

23. Venard, C., Vaillancourt, L. Penetration and colonization of unwounded maize tissues by the maize anthracnose pathogen Colletotrichum graminicola and the related nonpathogen $C$. sublineolum. Mycologia, New York, v. 99, n.3, p. 368-377, 2007a.

24. Venard, C., Vaillancourt, L. Colonization of fiber cells by Colletotrichum graminicola in wounded maize stalks. Phytopathology, Saint Paul, v. 97, p. 438-447, 2007b 